\title{
Ovarian Cancer and Primary Peritoneal Carcinoma pT1 TNM Finding v7
}

National Cancer Institute

\section{Source}

National Cancer Institute. Ovarian Cancer and Primary Peritoneal Carcinoma pT 1 TNM

Finding v7. NCI Thesaurus. Code C89642.

Ovarian cancer limited to ovaries (one or both). (from AJCC 7th Ed.) 